\title{
Estimating fire-related parameters in boreal forest using SPOT VEGETATION
}

\author{
R.H. Fraser ${ }^{a}, *$ Z. Li $^{b}$ \\ ${ }^{a}$ Natural Resources Canada, Canada Centre for Remote Sensing, 588 Booth Street, Ottawa, ON, Canada K1A 0Y7 \\ ${ }^{\mathrm{b}}$ Department of Meteorology and Earth System Science Interdisciplinary Center, University of Maryland, College Park, MD 20742-2425, USA
}

Received 12 June 2001; received in revised form 18 February 2002; accepted 15 March 2002

\begin{abstract}
The majority of burning in the boreal forest zone consists of stand replacement fires larger than $10 \mathrm{~km}^{2}$ occurring in remote, sparsely populated regions. Satellite remote sensing using coarse resolution $(\approx 1 \mathrm{~km})$ sensors is thus well suited in documenting the spatial and temporal distribution of fires in this zone. The purpose of this study was to investigate the utility of the SPOT VEGETATION (VGT) sensor for estimating three key parameters related to boreal forest fire: burned area, postfire regeneration age, and aboveground biomass. Based on a sample of fires across Canada, the best overall discrimination of burned forest was provided by a normalized short-wave-based vegetation index (SWVI) that combines near-infrared (NIR) and short-wave infrared (SWIR) channels from VGT. Multitemporal differencing of this index from anniversary date VGT composites was combined synergistically with active fire locations from NOAA/AVHRR to map Canadian forest that burned during 1998 and 1999. National burned area estimates for both years were within $15 \%$ of those compiled by the Canadian Interagency Forest Fire Centre. The normalized index also was correlated $(R=.68)$ with the age of regenerating forests in Saskatchewan and Manitoba that burned between 1949 and 1998. An artificial neural network (ANN) model developed using temporal metrics computed from VGT could predict the age of these forests with an RMS error of 7 years $(R=.83)$. By contrast, forest biomass based on Canada's Forest Inventory (CanFI) was estimated with relatively poor accuracy (RMS $=32$ tons/ha) from VGT reflectance and terrestrial ecozone using a network model. We conclude that the VGT instrument is effective for mapping large boreal burns at the end of a fire season and approximating the age of regenerating burns less than about 30 years old. This information can be useful to supplement conventional groundbased data sets in remote areas where coverage may be incomplete. (C) 2002 Published by Elsevier Science Inc.
\end{abstract}

\section{Introduction}

The boreal biome covers $17 \%$ of Earth's land area and comprises about $25 \%$ of its forestland. The major ecosystems within the boreal zone (forests, peatlands, and tundra) contain more than $30 \%$ of terrestrial carbon stores, thus representing a major component of the global carbon budget (Kasischke, 2000). Wildfires are a dominant factor controlling ecological succession and carbon storage in boreal forests, burning on average nearly $1 \%$ of the total forest area annually. Fire has an immediate direct impact on the carbon balance of boreal forests resulting from the conversion of living biomass and soil carbon into atmospheric carbon $\left(\mathrm{CO}_{2}, \mathrm{CO}, \mathrm{CH}_{4}\right)$. Amiro et al. (2001) estimated that

\footnotetext{
* Corresponding author. Tel.: +1-613-947-6613; fax: +1-613-947-1406

E-mail address: robert.fraser@ccrs.nrcan.gc.ca (R.H. Fraser).
}

between 1959 and 1999, forest fires in Canada released a mean annual $27 \mathrm{Tg}$ of carbon/year, equivalent to about $18 \%$ of current $\mathrm{CO}_{2}$ emissions from the Canadian energy sector. Emissions from Canadian fires have recently been shown capable of affecting atmospheric chemistry in the southeastern United States, more than $3500 \mathrm{~km}$ downwind from the source (Watowa \& Trainer, 2000). Fire also indirectly affects carbon cycling by modifying large-scale patterns of stand age distribution and thus total carbon storage of the boreal forest (Kasischke, 2000). In addition, a warming of the ground layer after fire may elevate the rate of $\mathrm{CO}_{2}$ release from microbial decomposition for more than a decade (Richter, O’Neill, \& Kasischke, 2000).

Due to the large extent and remoteness of the boreal zone, it is difficult and costly to monitor the distribution of fire activity across its entire area using conventional aerial or ground-based surveys. By contrast, coarse resolution $(\approx 1$ $\mathrm{km})$ satellite sensors are well suited to boreal fire mapping 
due to their ability to cover large areas on a daily basis, and the fact that large fires are responsible for the vast majority of burning. For example, in Canada between 1990 and 1995, fires larger than $10 \mathrm{~km}^{2}$ accounted for $97 \%$ of the burned forest area (Canadian Council of Forest Ministers, 1999). To date, the AVHRR sensor aboard the NOAA series of meteorological satellites has been the most commonly used spaceborne instrument for characterizing the distribution and impact of boreal fires at regional to continental scales. The sensor has been used for identifying active fires (Flannigan \& Vonder Haar, 1986; Li, Cihlar, Moreau, Huang, \& Lee, 1997; $\mathrm{Li}$ et al., 2000), detecting smoke plumes ( $\mathrm{Li}$, Khananian, \& Fraser, 2001), mapping the extent of burned areas (Cahoon, Stocks, Levine, Cofer, \& Pierson, 1994; Fraser, Li, \& Cihlar, 2000; Kasischke \& French, 1995; Li, Nadon, Cihlar, \& Stocks, 2000), and estimating trace gas emissions (Cahoon et al., 1994).

Much of the boreal forest zone appears as a patchwork of even-aged forests - the vestige of large stand replacement fires occurring over several decades (Stocks, 1991). These patterns have been mapped at a regional scale through classification of AVHRR (Cihlar, Beaubien, Xiao, Chen, \& Li, 1997; Steyaert, Hall, \& Loveland, 1997) and Landsat TM (Beaubien, Cihlar, Simard, \& Latifovic, 1999; Hall, Knapp, \& Huemmrich, 1997) imagery into categories representing broad stages of fire regeneration (e.g., recent burns, regenerating burns, higher density forest). Within the BOREAS study region located in Central Canada, Steyaert et al. (1997) estimated from unsupervised classification of monthly AVHRR/NDVI profiles that approximately $30 \%$ of the area had been affected by fire disturbance within the preceding 30-35 years. They also noted that Landsat TM composites (bands 5, 4, AND 3) were more effective than the AVHRR data for discriminating burns older than 15-20 years. Kasischke and French (1997) modeled the AVHRR/NDVI seasonal trajectory and peak for Alaskan white and black spruce forest as a function of fire regeneration age. The peak seasonal NDVI for black spruce forests (more common in Canada) occurred about 20 years after burning. Such empirical models of stand age could aid in constructing a baseline for predicting at regional and continental scales how changes in fire frequency will alter the age distribution and carbon storage of forests (Kasischke, Christensen, \& Stocks, 1995).

Biomass density is another important boreal forest parameter influenced by fire, and is necessary to estimate fuel loading and the amount of direct carbon emissions resulting from fire (French et al., 2000). Remote sensing of biomass in northern conifer forests has been most effective with synthetic aperture radar (Ranson et al., 1997) and scanning lidar (Lefsky et al., 1999), while reflectance data from Landsat TM also have been applied successfully over even aged, productive forest stands (Fazakas, Nilsson, \& Olsson, 1999). A physically based approach for estimating canopy biomass density in the BOREAS study region was developed by Hall et al. (1997). This technique related tree volumetric density to sunlit canopy fraction, which was derived using a canopy reflectance model and TM-measured reflectance.

The recent SPOT VEGETATION (VGT) sensor provides imagery with a swath size and return interval comparable to AVHRR and includes a $1.65-\mu \mathrm{m}$ short-wave infrared (SWIR) channel also found on the new AVHRR instrument onboard post-NOAA14 satellites. Preliminary studies have shown that VGT's SWIR channel is highly effective for discriminating burned boreal forest (Eastwood, Plummer, Wyatt, \& Stocks, 1998; Fraser, Li, \& Landry, 2000), which is consistent with previous work using other sensors over a wide range of ecosystems (Eva \& Lambin, 1998; also summarized in Pereira et al., 1999). In addition to being sensitive to burned area, SWIR reflectance measured by Landsat TM has been found related to the age and biomass of secondary forests in Brazil (Steininger, 2000) and lodgepole pine forests in Wyoming, USA (Jakubauskas $\&$ Price, 2000). This suggests that a relationship may similarly exist between SWIR reflectance and both postfire regeneration age and biomass at a coarser scale in boreal forest.

The purpose of this research was to investigate the utility of the sensor for measuring three key parameters related to boreal forest fire: burned area, postfire regeneration age, and forest biomass. The specific objectives were to:

1. quantify changes in VGT-measured reflectance and vegetation indices (VIs) after boreal forest is burned;

2. map forest burned in Canada during 1998 and 1999 using the results from (1) and a change detection algorithm developed for annual burned area mapping;

3. investigate the potential to predict postfire regeneration age using multiple regression and artificial neural network (ANN) approaches applied to VGT channels, VIs, and multitemporal metrics; and

4. examine the relationship between VGT reflectance and aboveground forest biomass.

\section{Methods}

\subsection{Satellite sensor data}

SPOT VGT 10-day composites (S10 syntheses) covering all of Canada were acquired for the period April 1-October 31 of 1998 and 1999. The 42 syntheses provide surface reflectance in four channels $[0.45 \mu \mathrm{m}$ blue, $0.66 \mu \mathrm{m}$ red, $0.83 \mu \mathrm{m}$ near-infrared (NIR), and $1.65 \mu \mathrm{m}$ SWIR], which were nominally corrected for atmospheric effects using the Simplified Method of Atmospheric Correction (Rahman \& Dedieu, 1994). We projected the imagery from Plate Carree to Lambert Conformal Conic at $1-\mathrm{km}$ resolution using nearest neighbor resampling. The composite imagery was further corrected for bidirectional reflectance effects by 
normalizing to a $45^{\circ}$ solar zenith angle and nadir view using a new nonlinear, temporal BRDF model (Latifovic, Cihlar, \& Chen, in press). Finally, individual pixels contaminated by atmosphere (e.g., subpixel cloud or smoke) or other effects were identified and replaced using CECANT (Cloud Elimination from Composites using Albedo and NDVI Trend; Cihlar, 1996). CECANT is a self-calibrating method that identifies contaminated pixels based on their seasonal NDVI trajectories and red reflectance. Two VIs (VI) were computed from the corrected channels: NDVI [(NIR - red)/ (NIR + red)] and an analogous short-wave-based vegetation index (SWVI), in which the SWIR is substituted for the red [i.e., (NIR - SWIR)/(NIR + SWIR)] (Fraser et al., 2000; Kaufman \& Remer, 1994).

\subsection{Measuring changes in VGT reflectance and VI after burning}

To determine the most effective VGT channels and VI for annual burned area mapping across Canada, post fire season composites were produced for 1998 and 1999. Cloud-free 30-day composites were created for September of each year by selecting pixels with smallest NIR reflectance from three September 10-day maximum NDVI syntheses. Since cloud has high NIR reflectance and burns have low reflectance, this minimum NIR criterion minimizes any residual cloud contamination in the 10-day products, while preferentially selecting pixels in their burned state if they burned during the September compositing period (Barbosa, Pereira, \& Gregoire, 1998). By contrast, the conventional maximum NDVI criterion used for the 10-day composites would be biased to selecting September fire pixels in their unburned condition, causing them to go undetected. In this application, the 30-day minimum NIR criterion is designed to reduce the impact of the potential bias in the 10-day composites. A postfire composite based on October imagery could have been used to avoid overlap with late-summer fires, but at the expense of degrading contrast of burned areas due to annual senescence of deciduous species (i.e., trees, shrubs, and herbaceous vegetation) within the surrounding unburned conifer forest (Kasischke \& French, 1997).

A sample of forested pixels burned in 1999 was identified to examine reflectance changes occurring in the same year of burning (i.e., between September 1998 and September 1999). One hundred forty-five polygons (2643 pixels) containing burned forest across Canada were digitized on-screen with reference to a backdrop consisting of the September 1999 VGT composite (RGB=SWIR, NIR, and red), in which recent burns appear dark red. A mask of 1999 hotspot locations produced by compositing daily AVHRR fire products ( $\mathrm{Li}$, Nadon, \& Cihlar, 2000) was overlaid on the VGT imagery to aid in locating the 1999 burns. A second sample containing 340 pixels was digitized from nine fires that occurred in May 1999, during the early part of the fire season. This sample was used to investigate if spring fires have a significantly different burn signature at the end of the fire season. To examine VGT spectral changes occurring the year after forest is burned (i.e., from September 1998-1999), a third sample consisting of 162 polygons (2504 pixels) were similarly identified for forest that burned in 1998. In all three samples, water pixels were masked from the polygons based on an AVHRR classification (Cihlar, Beaubien, Latifovic, \& Simard, 1998). Simple reflectance and VI statistics were then computed for the three sets of sample pixels using the two anniversary date composites from September 1998 and 1999. Due to severe atmospheric effects from path radiance, VGT's blue channel was not examined in this study.

\subsection{Annual mapping of burnt forest across Canada (1998 and 1999)}

Fraser, Li, and Cihlar (2000) developed a technique for annual burned area mapping of boreal forest. The method, dubbed HANDS (Hotspot and NDVI Differencing Synergy), combines multitemporal change detection with active fire monitoring. In conventional spectral change detection approaches (e.g., image differencing), a significant challenge is to establish a threshold suitable for identifying those pixels that have undergone change. Land cover change detection techniques also are susceptible to producing false positives due to factors other than real cover change, such as cloud contamination, image misregistration, and phenological variation. HANDS is designed to minimize these problems by using an annual mask of satellite-detected fire locations as training pixels to derive spatially variable thresholds for separating burned pixels. Since the resulting clusters of burned pixels are required to be spatially coincident with the active fire mask, change pixels not associated with burning are largely eliminated. The processing steps required by the procedure are illustrated and described in Fig. 1 using AVHRR data. More detailed information is presented in Fraser, Li, and Cihlar.

The HANDS procedure requires three types of input data: (1) pre- and postfire composite images used for multitemporal differencing; (2) a mask of annual active fire locations; and (3) a vegetation mask or land cover classification. A previous application of the technique for mapping boreal forest burns relied on NOAA/AVHRR for all three inputs (Fraser, Li, \& Cihlar, 2000). In the present work, we applied the technique in a similar manner across Canada for 1998 and 1999, but for the multitemporal differencing, we substituted an optimal change metric from VGT in place of the NDVI from AVHRR. Based on the analysis of individual channels and VIs (previous section), the VGT channel or index demonstrating the largest average change after burning was derived from the composite imagery and used for differencing. For mapping 1998 burns, a prefire composite was created by combining 10-day VGT composites for the period April 20-May 20 of 1998 (the VEGETATION instrument was launched in March 1998, 
(a) AVHRR annual hotspots

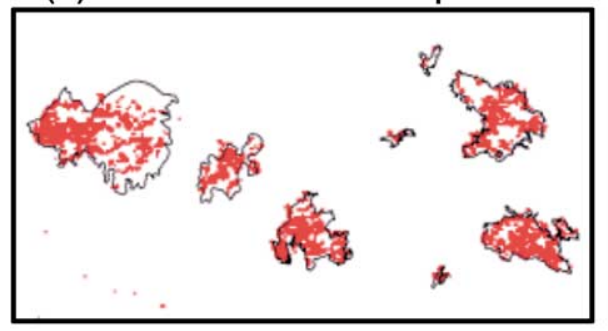

(c) Apply regional difference threshold (b) Vegetation index difference

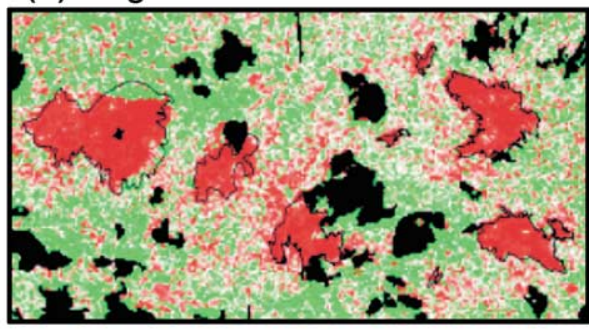

(d) Filter then group burn clusters

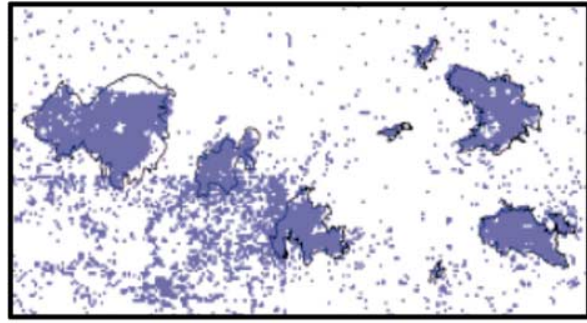

(e) Apply local difference threshold

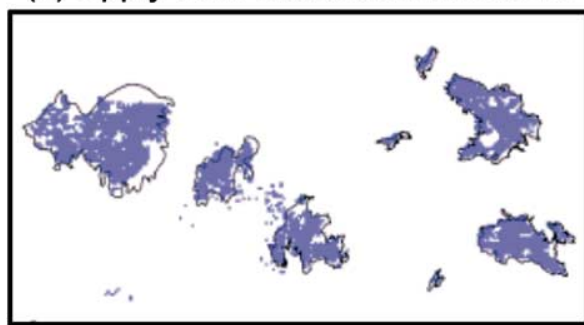

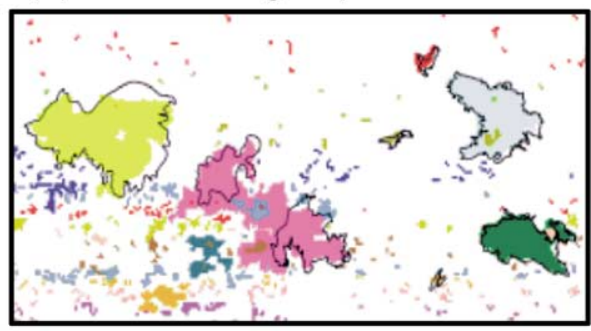

(f) Eliminate bums with no hotspots

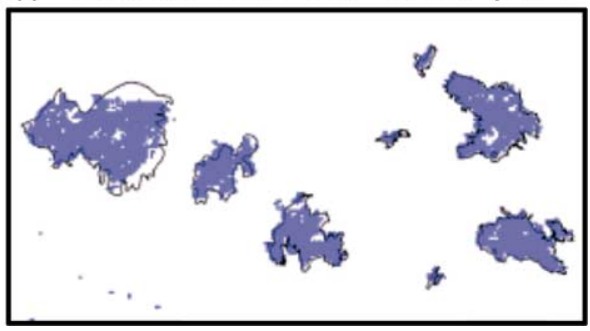

Fig. 1. Key processing steps for the HANDS burn mapping algorithm. The colour palette in (b) ranges from red (large NDVI decrease) to light red (small NDVI decrease) to white (little NDVI change) to dark green (NDVI increase) with lakes shown in black. Individual burn clusters are shown using separate colours in (d). Provincial burn boundaries produced from aerial photointerpretation are shown in black. An annual composite of active fire locations from AVHRR (a) is first used to derive regional-level $(200 \times 200 \mathrm{~km})$ difference thresholds from a pair of anniversary date, VI composites (b). The thresholds are computed based on the mean and standard deviation of the decrease in the VI for fire locations within each region. This initial threshold separates all burned pixels as well as many nonburned pixels (c; note the larger number of pixels selected in the lower left portion, which are located in a separate 200-km block with a more liberal NDVI difference threshold). The patches of potentially burned pixels are then separated using a modal filter and grouped into contiguous burn clusters, each with a unique identity (d). Active fires contained within the clusters are used to derive local, burn-specific differencing thresholds that again are based on the mean and standard deviation of the observed hotspot NDVI drop (e). In the last step, any burn clusters containing less than $10 \%$ active fires are presumed false and eliminated (f).

precluding the use of an anniversary date composite from September 1997). A maximum NDVI criterion was used to combine the three spring 10-day composites so that any pixels burned during the compositing period would be selected in their unburned state. The postfire composite for 1998 burn mapping consisted of the combined three 10-day VGT syntheses from September of that year described in the previous section. Burnt area mapping for 1999 was accomplished by differencing the September composites from 1998 and 1999.

\subsection{Estimating postfire regeneration age}

The utility of VGT imagery for predicting postfire regeneration age was investigated using a successional chronosequence identified from historical forest fire records compiled for Saskatchewan and Manitoba in digital format. Vector GIS records cover the period 1945-1996 for Sas- katchewan (Naelapea \& Nickeson, 1998) and 1980-1991 for Manitoba (Stocks, Zepp, \& Knapp, 1998). The polygon vectors for each year were merged into one polygon data set, then reprojected and rasterized to a $1-\mathrm{km}$ resolution grid in Lambert Conformal Conic projection. These historical data were supplemented with 1994-1998 fire locations determined from annual masks of NOAA/AVHRR fire hotspots ( $\mathrm{Li}$ et al., 2000). The study region, indicated by the shaded area in Fig. 2, is contained mainly within the Boreal Taiga and Boreal Shield ecozones. The most common land cover types are spruce (Picea spp.) and jack pine (Pinus banksiana) conifer forests in varying stages of fire regeneration, wetlands, and lakes. Open lichen woodlands are dominant in the northerly portion of the study area, while mixed coniferous-deciduous forests are common in the south.

To make allowance for positional uncertainties in the historical fire databases (Naelapea \& Nickeson, 1998; 


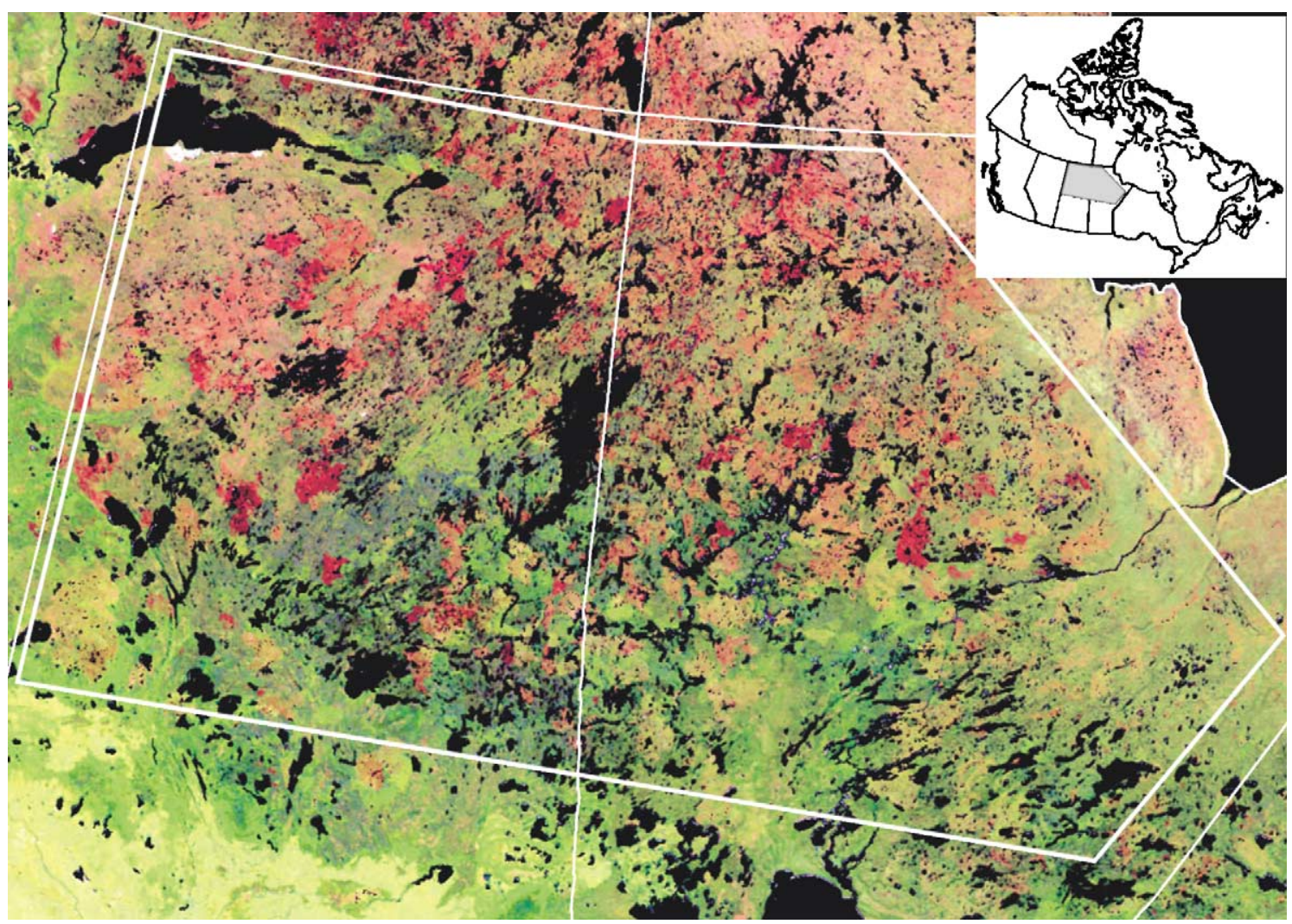

Fig. 2. Study area within Manitoba and Saskatchewan spanning approximately $1150 \times 750 \mathrm{~km}$ used for predicting postfire regeneration age with SPOT VGT. The background image is a contrast-stretched composite of averaged June-September 1999 reflectance from VGT's SWIR, NIR, and red channels $(\mathrm{RGB}=\mathrm{SWIR}, \mathrm{NIR}$, and red).

Stocks et al., 1998) and the large interannual differences in burned area, small polygons were manually digitized within the interior of the historical fire polygons and satellite hotspot clusters. If the polygons for a given year provided fewer than 100 sample pixels, they were deemed potentially unrepresentative and not included in the analysis. A total of 485 polygons were digitized across both provinces from 1949 to 1998 burn locations, providing 17,349 sample pixels after masking land cover types not containing conifer forest, including agriculture, water, and deciduous forest (Cihlar et al., 1998). These pixels were then randomly separated into training $(50 \%)$, cross-validation $(10 \%)$, and testing $(40 \%)$ subsets.

The spectral signatures of the historical burns were characterized using SPOT VGT 10-day syntheses from the snow-free period June 1-September 30 of 1999. The average reflectance or VI value was computed from the red, NIR, SWIR, NDVI, and SWVI channels. Three multitemporal metrics (maximum, minimum, and range) derived for each channel from the 4-month period were also examined. These metrics computed from multitemporal AVHRR data have been shown to aid in characterizing the phenological cycle of vegetation and discriminating vegetation types (DeFries, Hansen, \& Townshend, 2000). Similarly, monthly AVHRR/NDVI trajectories have been used to improve separability of boreal forest cover types (Steyaert et al., 1997). As recommended by Kimes, Holben, Nickeson, and McKee (1996), spatially smoothed channels also were created by applying a median $3 \times 3$ filter to the five mean channels, thus providing a total of 25 input channels.

The relationships between the remote sensing variables and burn regeneration age were first assessed independently using simple regressions calculated from the full digitized sample. Multivariate predictive models of burn age were then constructed using both multiple regression and ANN approaches. Forward stepwise and backward elimination multiple regression models were developed using the combined training and cross-validation data sets $(60 \%$ of data). A probability of .05 was used for entering or removing variables. Second-degree polynomial terms were also tested for each variable in the single and multiple regressions to account to for simple curvilinear relationships with burn age. The regression models were then assessed by computing the RMS error and correlation coefficient between the predicted and actual burn age from the 6933 test pixels.

ANNs are being increasingly applied in remote sensing as a nonparametric approach for predicting vegetation characteristics and classifying land cover (Foody, Lucas, Curran, \& Honzak, 1996; Gopal, Woodcock, \& Strahler, 
1999; Kimes, Nelson, Manry, \& Fung, 1998). ANNs are distributed, adaptive, nonlinear learning machines built from simple processing elements, or neurons (Principe, Euliano, \& Lefebvre, 2000). In this study, the conventional multilayer perception ANN was used with one hidden layer of neurons to predict postfire regeneration age (see Paola \& Schowengerdt, 1995, for a more detailed description). Networks employing the hyperbolic tangent activation function and containing a varying number of hidden layer neurons (5-35 in steps of 5) were compared. Network training was stopped when the average RMS error computed for the independent cross-validation pixels began to increase or the network had performed 10,000 training iterations. This prevented the network from overlearning the training data so that it would perform well with unseen data. Depending on the number of hidden layer neurons, between 208 and 3239 iterations were required. Once trained, the network weights were frozen and the ANN was used in forward mode to predict regeneration age in the test pixels.

\subsection{Estimating forest biomass}

The relationship between aboveground forest biomass and VGT reflectance was investigated using biomass data derived from Canada's 1991 Forest Inventory (CanFI; Lowe, Power, \& Gray, 1996). Aboveground biomass in tons per hectare within 47,000 forest inventory polygons has been estimated from allometric equations applied to stand variables (height, diameter, and density) from CanFI site class, age class, and species (Penner, Power, Muhairwe, Tellier, \& Wang, 1997). From this data set, $10-\mathrm{km}$ resolution rasterized grids were created representing biomass of productive forests organized by species and age class for the variable area that was inventoried within each cell. We computed biomass density ( $t / \mathrm{ha}$ ) of all tree species within each $10-\mathrm{km}$ cell by dividing the summed species and age class grids ( $t$ ) by the inventoried area within each cell (ha).

Pearson correlations were calculated between biomass density and the averaged June 1-September 30 of 1999 reflectance or VI value computed for the red, NIR, SWIR, NDVI, and SWVI channels from VGT. These channels were averaged within the $10-\mathrm{km}$ biomass cells by selecting only those pixels that are classified as forest in a 1998 VGT land cover classification. This excluded nonforest cover types as well as recently burned forest that would not be represented in the 1991 CanFI. Predictive models of biomass were developed using the ANN approach described previously, with a random $50 \%$ training, $10 \%$ cross-validation, and $40 \%$ testing sample. The location of the $10-\mathrm{km}$ cells within 11 Canadian terrestrial ecozones was considered as a potential stratifying variable for predicting biomass by adding binary indicator (dummy) variables to the ANN model. The ecozones represent large, generalized ecological units in Canada characterized by interactive abiotic and biotic factors (Ecological Stratification Working Group, 1996).

\section{Results and discussion}

\subsection{Measuring changes in VGT reflectance and VI after burning}

Fig. 3 shows the average reflectance (red, NIR, and SWIR) and VI values (NDVI and SWVI) computed for the three sets of sample burned pixels from the September 1998 and 1999 composites. A quantitative index of the separability between burned and nonburned forest afforded by each channel and VI was computed for the 1999 fires as (Eq. (1)):

$S=\left|x_{\mathrm{b}}-x_{\mathrm{nb}}\right| /\left(s_{\mathrm{b}}+s_{\mathrm{nb}}\right)$

where $S$ is the separability index, $x_{\mathrm{b}}$ is the mean reflectance or VI from burned forest, $x_{\mathrm{nb}}$ is the mean reflectance or VI from nonburned forest, $s_{\mathrm{b}}$ is the standard deviation of reflectance or VI from burned forest, and $s_{\mathrm{nb}}$ is the standard deviation of reflectance or VI from nonburned forest. The index, denoted by an "S" in Fig. 3, provides a measure of the channel signal-to-noise ratio. A value greater than 1 indicates that the standard deviations of burned and nonburned forest do not overlap, allowing good separation (Kaufman \& Remer, 1994).

The uppermost pair of bars for each channel shows the average signature from all 1999 fires in their preburn (September 1998) and postburn (September 1999) condition. In the red channel, reflectance of burned forest measured at the end of the fire season decreased, presumably due to strong absorption from char combustion products (Pereira et al., 1999). As is widely observed in boreal and other ecosystems, NIR reflectance demonstrated the strongest change after

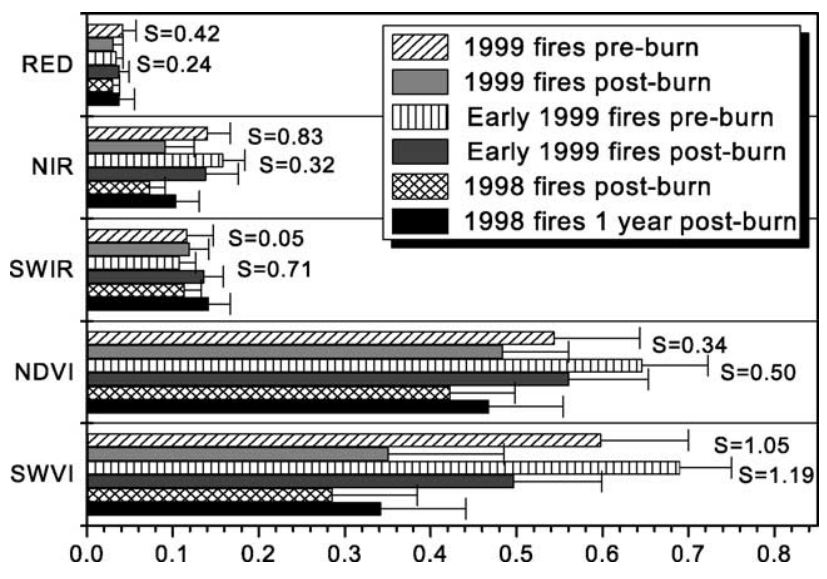

Fig. 3. Mean reflectance and VI values computed from 1998 and 1999 September VGT composites for three sets of sample burned pixels (the SWVI has been shifted up by 0.5 to make values positive). The uppermost pair of bars for each channel indicates the average signature of all 1999 fires in their preburn (September 1998) and postburn (September 1999) condition. The middle pairs of bars represent the pre- and postburn signature from nine spring fires from 1999, while the bottom pairs show changes in 1998 burned forest from the same year of burning (September 1998) to 1 year after burning (September 1999). 
burning $(S=0.83$ ), decreasing significantly due to the destruction of highly scattering, leafy vegetation (Pereira et al., 1999). SWIR reflectance of vegetation is strongly controlled by water absorption, and would be expected to increase with the destruction of healthy vegetation with high water content (de Boer, 1993). In addition, the removal of tree canopy after crown fire should lessen shadowing effects present in mature forest, also producing an elevated SWIR response. However, the observed SWIR increase of forest burned in 1998 was relatively small in relation to its variance ( $S=0.05$; see discussion in following paragraph). The NDVI exhibited a modest decrease $(S=0.34)$ after burning by comparison to NIR reflectance, due to the concomitant decrease in red reflectance. In fact, in some northerly forests subject to late-season fires, NDVI changed very little owing to a large drop in red reflectance. By combining the NIR and SWIR channels, the SWVI provided the best overall discrimination of burned forest at the end of the fire season $(S=1.05)$ owing to the large drop in NIR and small increase in SWIR reflectance. In general, VIs that combine NIR and mid-IR channels are highly effective for distinguishing a variety of burned vegetation types (Barbosa, Gregoire, \& Pereira, 1999; Pereira, 1999; Pereira et al., 1999).

A case study by Fraser et al. (2000) examined a time series of single-date VGT images ( $P$ products) covering a 154,094-ha fire that occurred in Alberta, Canada during May 1998. Reflectance in the red, NIR, and SWIR channels initially decreased relative to surrounding unburned forest.
However, by late August, both red and SWIR reflectance had increased significantly, contrary to the above average results for 1999 burned forest. Nine early season fires occurring in May 1999 were therefore examined separately in an attempt to resolve this discrepancy. In the case of these spring fires (second pair of bars in Fig. 3), red reflectance increased by the end of the fire season, NIR reflectance decreased, and SWIR increased significantly. The most logical explanation for the differences observed in September reflectance between spring and summer fires is the contrasting reflectance of the initial combustion residues and subsequent herbaceous regeneration. By the end of the fire season, the influence of charred vegetation in spring fires (which strongly absorbs radiation in the red and SWIR) was largely replaced by that of the early successional, herbaceous vegetation. Moreover, early season fires may cause less damage to a frozen or moist ground layer, leading to a more rapid regeneration (Kasischke \& French, 1997). By contrast, in many August fires, the signal from the combustion products continued to dominate several weeks later towards the end of the fire season.

The third pair of bars in Fig. 3 shows changes in the signature of 1998 burned forest that occurred between the same year of burning (September 1998 imagery) and 1 year after burning (September 1999 imagery). The trend of increasing reflectance in the red and SWIR resulting from regeneration is the same as that observed in the early 1999 fires. Contrast with surrounding unburned vegetation gen-

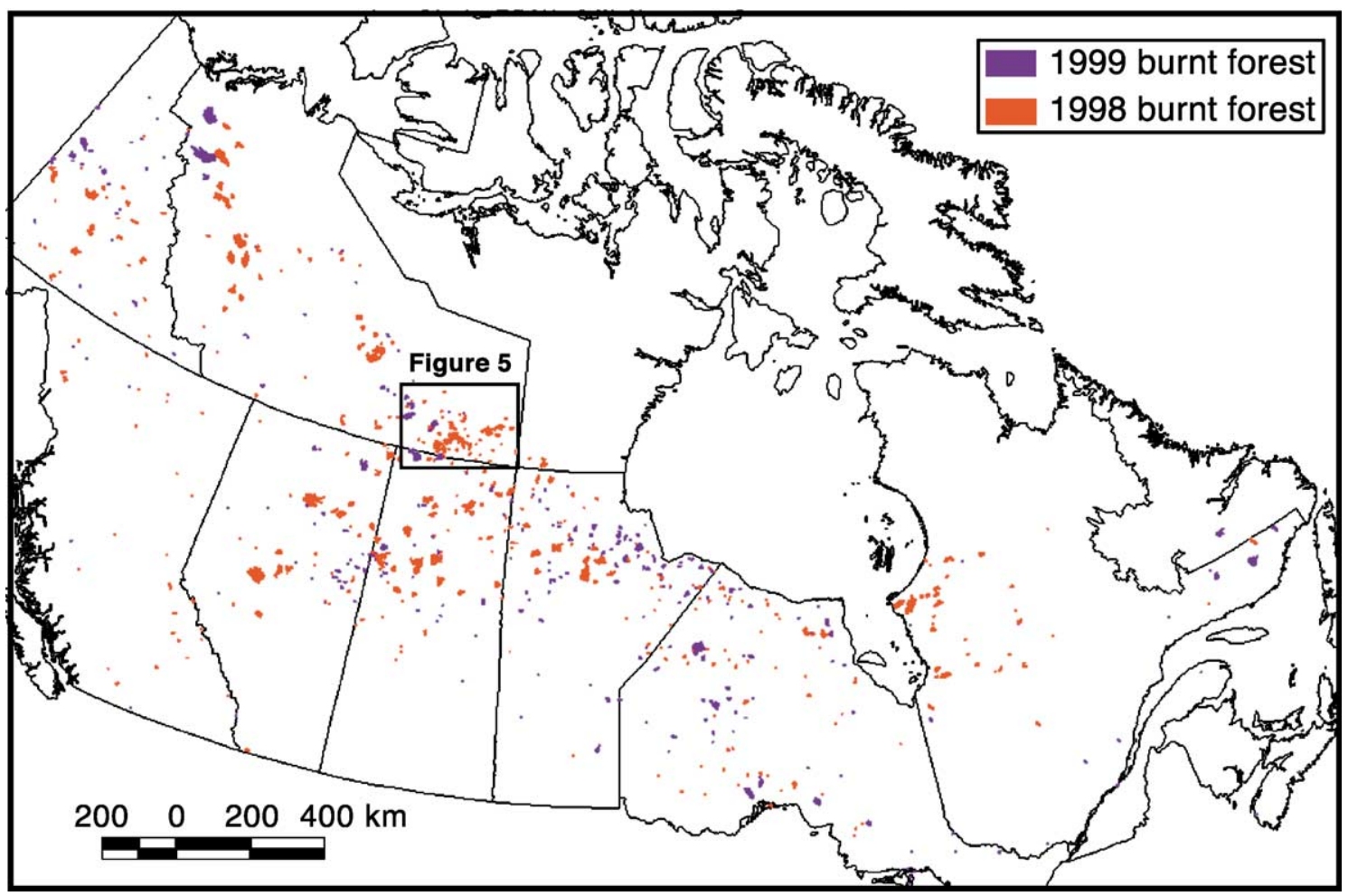

Fig. 4. Forest burned in Canada between 1998 and 1999 as mapped using SPOT VGT differencing combined with NOAA/AVHRR hotspots. The box indicates the region in central Canada shown in close-up in Fig. 5. 
erally became much stronger in these two channels 1 year after burning. After one full year of regeneration, NIR reflectance and NDVI recovered significantly toward preburn levels.

\subsection{Annual mapping of burnt forest across Canada (1998 and 1999)}

Several previous applications using coarse resolution imagery for burned area mapping in the boreal zone have examined postfire decreases in AVHRR's NDVI (Fraser, Li,
\& Cihlar, 2000; Kasischke \& French, 1995; Li et al., 1997; Li, Nadon, Cihlar, \& Stocks, 2000). In the preceding section, it was demonstrated that an SWVI provides superior discrimination of burned boreal forest at the end of the fire season than does the NDVI or individual VGT channels. This index was therefore used for the multitemporal differencing component of the HANDS algorithm to map areas burned in Canada during 1998 and 1999.

Canada-wide results of applying the algorithm to the VGT composites and AVHRR hotspots for 1998 and 1999 are shown in Fig. 4. In both years, the majority of burning
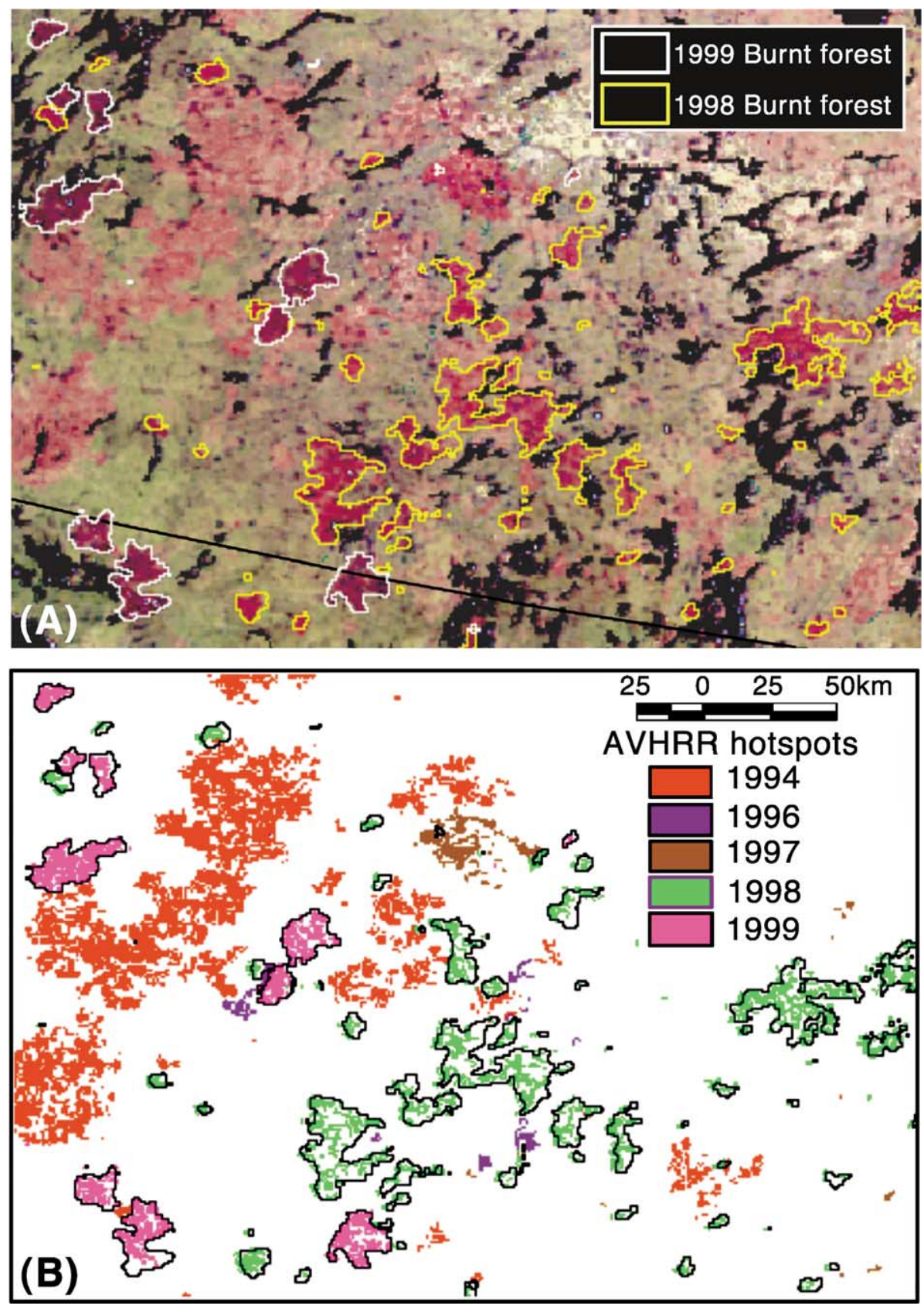

Fig. 5. (A) Burn perimeters in central Canada mapped using VGT for 1998 and 1999 superimposed on a VGT false colour composite (RGB= SWIR, NIR, and red). (B) Annual masks (1994 and 1996-1999) of active fires detecting using NOAA14/AVHRR and a boreal fire detection algorithm. A comparison of the SWVI (C) and NDVI (D) for the region is also presented with lakes coloured blue. 

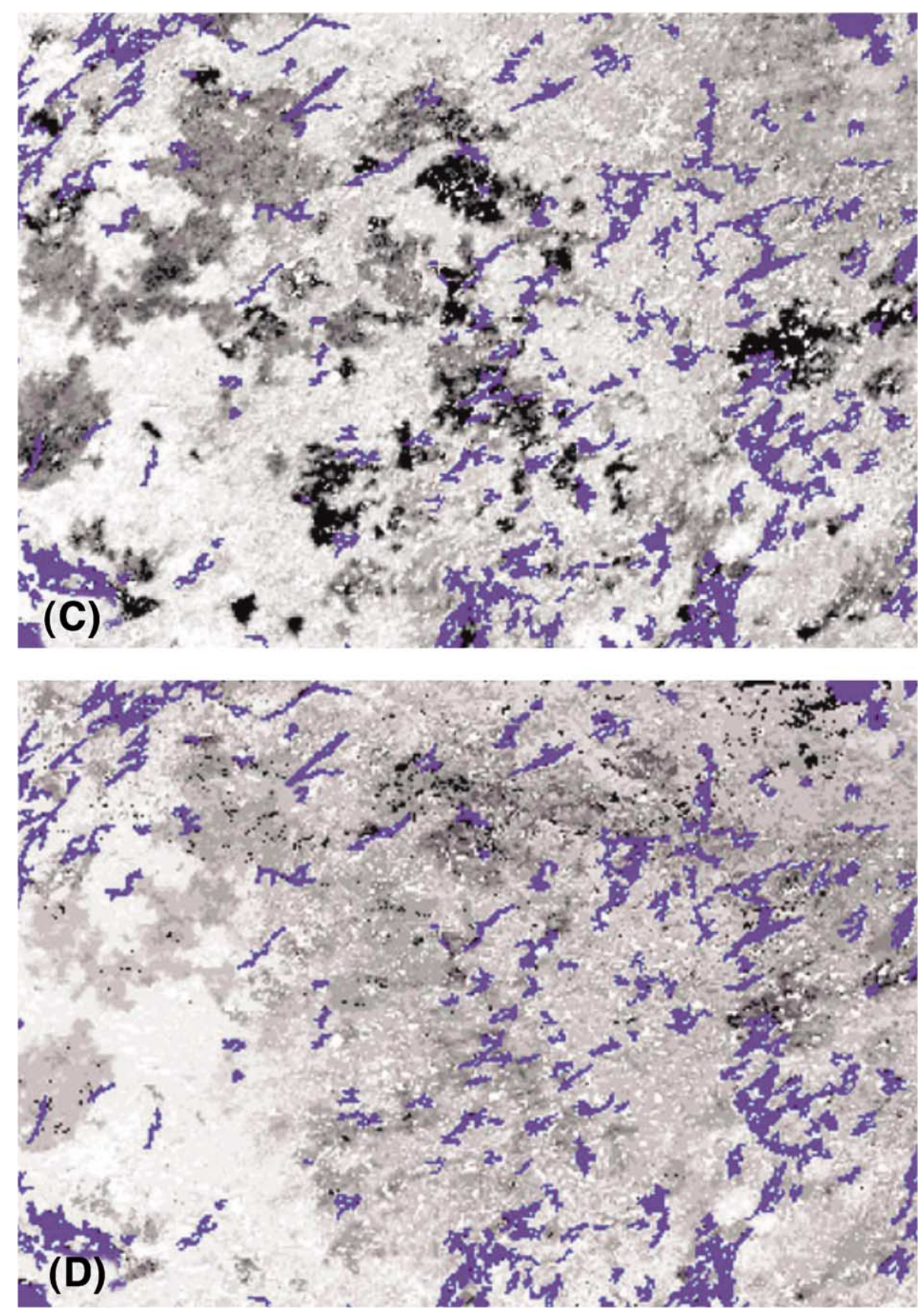

Fig. 5 (continued).

was attributable to wildfires $>100 \mathrm{~km}^{2}$ occurring in sparsely populated areas of Canada north of $55^{\circ}$. Fig. 5A shows a close-up of the extracted burn perimeters in central Canada superimposed over a September 1999 false-colour composite $(\mathrm{RGB}=\mathrm{SWIR}, \mathrm{NIR}$, and red). The burned area product is shown to have low errors of omission and commission in relation to 1998-1999 AVHRR hotspot locations (Fig. 5B) and recent, dark red burn scars visible in the postfire VGT composites (Fig. 5A). The location of several older burns, as indicated by the 1994, 1996, and 1997 hotspot locations remain clearly visible in the composite image as lighter shades of red. A comparison of the SWVI (Fig. 5C) and
NDVI (Fig. 5D) for the same region illustrates the enhanced contrast of recent and older burned areas provided by SWVI. National forest burned area from the VGT/AVHRR algorithm was 4,074,700 ha in 1998 and $1,901,300$ ha in 1999 , which is within $15 \%$ of estimates compiled by the Canadian Interagency Forest Fire Centre from provincial fire agencies $(4,710,775$ ha in 1998 and $1,705,645$ ha in 1999).

A spatially explicit evaluation of the burn mask was made using forest fire boundaries mapped by Alberta Environment using GPS surveys and aerial photo interpretation $\langle\mathrm{http}: / /$ www.gov.ab.ca/env/forests/fpd/ $\rangle$. Fig. 6 shows a typical area 


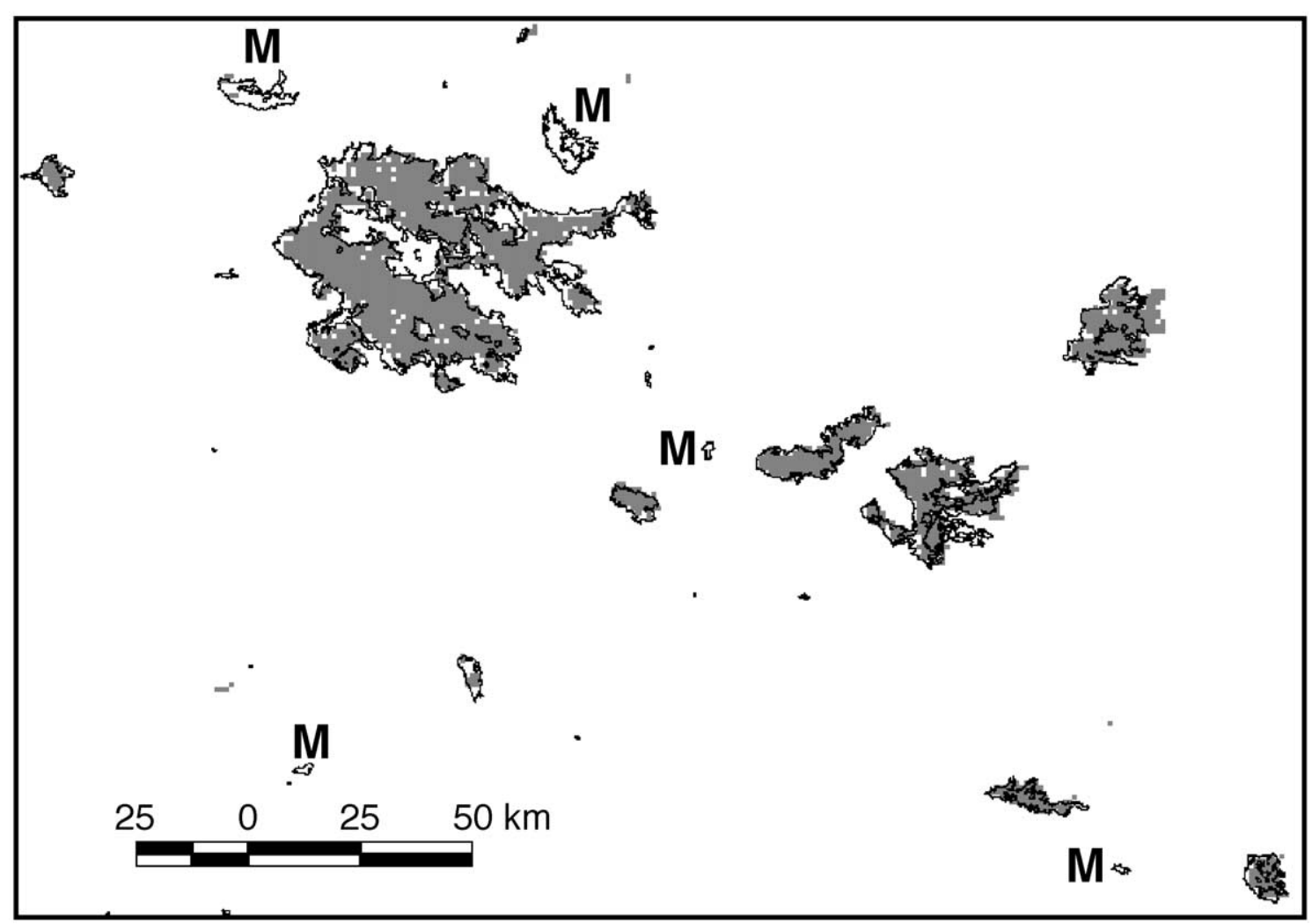

Fig. 6. 1998-1999 burns mapped in central Alberta using SPOT VGT (shaded areas) with Alberta Environment fire boundaries superimposed (black lines). "M" indicates burns that were not mapped using the satellite-based algorithm because no active fires were detected within them. The two larger missed burns cover 5258 and 5618 ha.

where, in most cases, burn boundaries derived using VGT compared favorably to the boundaries mapped by Alberta Environment. One constraint of the HANDS method is that burns can be mapped only if AVHRR hotspots were detected within them. This caused the omission of some burns, such as those denoted by an "M" in Fig. 6. Note that, smaller fires are often not detectable using AVHRR due to cloud cover and limited satellite diurnal sampling. However, for the 13 burns in Alberta that exceeded 10,000 ha, regression analysis indicated a strong linear relationship between the satellite $(S)$ and conventionally $(C)$ mapped areas $\left[C\right.$ (ha) $=1.14(S)-296$ ha, $R^{2}=.98, P<.005$, S.E. $=$ $2397 \mathrm{ha}$. Together, these fires comprised only a fraction of the province's 3051 wildfires from 1998 to 1999 , yet fully accounted for $75 \%$ of the total burned area. Across Alberta, the satellite algorithm estimated a 1998-1999 burned area of 638,700 ha, which was 86,700 ha or $12 \%$ smaller than the area of complete and partial burning mapped by the conventional surveys.

A national-scale validation of the burned area product is being conducted as part of the Natural Resources Canada Fire M3 project 〈http://fms.nofc.cfs.nrcan.gc.ca/FireM3/〉 using burns mapped at $30-\mathrm{m}$ resolution from 56 Landsat TM and ETM+ scenes. A comparison of the VGT and TM burn perimeters from two typical fires is presented in Fig. 7. For these burns and in most other cases, there is good general agreement between the outer burn boundaries mapped at the 30- and 1000-m resolutions. However, VGT area estimates are almost consistently larger because the sensor resolution is not sufficient to discern most interior islands containing unburned tree crowns, which are thus mapped as burned. As part of this validation, a statistical calibration relating Landsat TM and SPOT VGT burn area will be derived by double sampling 187 fires. The influence of burn size, fragmentation, terrestrial Ecozone, and fuel type on the TM-VGT relationship will also be quantified.

\subsection{Estimating postfire regeneration age and forest biomass}

Table 1 summarizes the association between age of regenerating burned forest and the temporal metrics computed from the SPOT VGT channels and two VIs. The correlation coefficient $(R)$ or multiple $R$ is shown depending on whether a second-degree polynomial term indicated a curvilinear relationship (i.e., $P<.05$ ). Fig. 8 shows plots of regeneration age against the mean value for the best metric computed from the NIR and SWIR channels and two VIs. The channel most strongly related to age was the SWIR, followed by the NIR and red. SWIR reflectance gradually decreased with regeneration age due to canopy shadowing (Nilson \& Peterson, 1994) and water absorption from increasing leaf area (de Boer, 1993). However, this decrease 
(a)

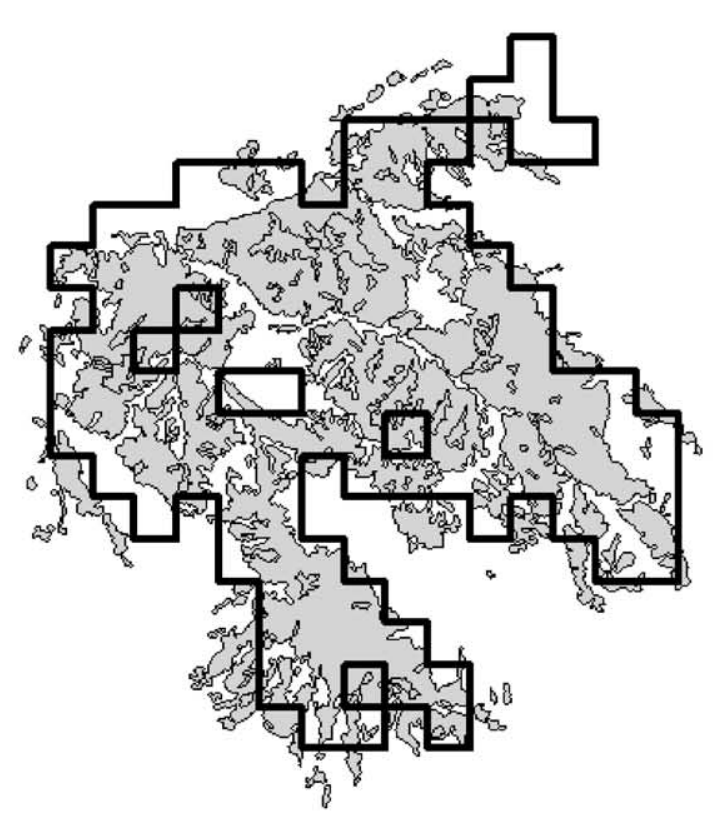

(b)

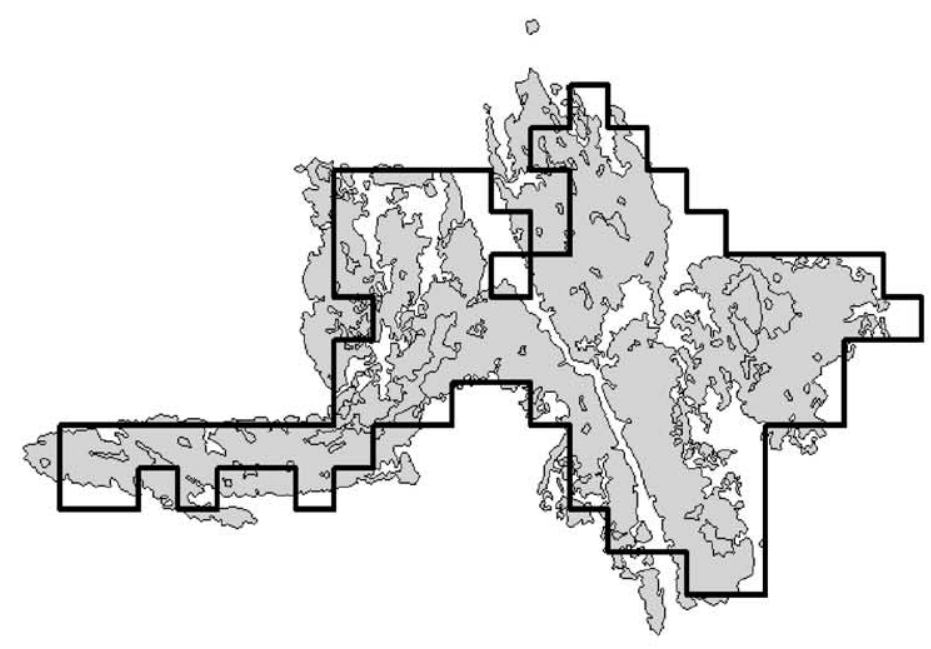

Fig. 7. Burned area perimeters derived using 1-km resolution SPOT VGT imagery (thicker lines: refer to 1-km pixel size for scale) and 30-m Landsat TM imagery (shaded). (a) 1999 fire from Yukon Territory. (b) 1998 fire in Northwest Territories.

did not begin until about 7 years on average, when vegetation became sufficiently dense to mask the more strongly absorbing combustion products (e.g., charred tree boles). Note that the temporal resolution of the annual time series is not sufficient to indicate an initial SWIR decrease relative to background forest (represented by the horizontal lines in Fig. 8), which was previously observed immediately after burning before reestablishment of herbaceous vegetation (Fraser et al., 2000). Of all channels and VIs, the SWVI was most closely related to burn regeneration age, exhibiting a linear relationship that explained almost $50 \%$ of its variation. Unlike the NDVI, the SWVI revealed a complex mosaic of regeneration patterns (e.g., Fig. 5C) where the boundaries of burns more than 15 years old were often clearly visible.

Table 1

Correlation coefficient $(R)$ or multiple $R$ (in the case of a significant seconddegree polynomial term) between regeneration age and temporal metrics (mean, spatially smoothed mean, maximum, minimum, and range from growing season) computed from SPOT VGT channels and two VIs $(n=17,349)$

\begin{tabular}{lccccc}
\hline Temporal metric & \multicolumn{6}{l}{ SPOT VGT channel or VI } \\
\cline { 2 - 6 } & Red & NIR & SWIR & NDVI & SWVI \\
\hline Mean & .012 & .344 & .450 & .362 & .663 \\
Smoothed Mean & .097 &. $\mathbf{3 5 7}$ &. $\mathbf{4 8 7}$ &. $\mathbf{3 8 2}$ & $\mathbf{. 6 8 2}$ \\
Maximum & .135 & .307 & .461 & .345 & .573 \\
Minimum &. $\mathbf{2 5 9}$ & .348 & .349 & .287 & .664 \\
Range & .203 & .077 & .133 & .146 & .095 \\
\hline
\end{tabular}

The metric providing the strongest correlation for each channel or index is highlighted in bold.
Results from the multiple regression and ANN models, which examined all 25 VGT metrics, are summarized in Table 2. Forward stepwise and backward elimination multiple regression produced identical models with 15 independent variables at the $5 \%$ significance level, explaining $58 \%$ of the variability in burn regeneration age in the test set with an RMS error of 8.06 years. The addition of second-order polynomial terms to account for simple nonlinearity increased the $R^{2}$ to .64 and decreased the RMS error to 7.58 in the training set, yet provided poorer prediction in the test set. The six ANN models containing between 5 and 35 neurons were consistently better predictors of burn regeneration age, with the $R^{2}$ between predicted and actual burn age ranging from .65 to .69 and RMS ranging between 6.97 and 7.33 years. A network containing 10 neurons provided the highest coefficient of determination $\left(R^{2}=.69\right)$ and smallest RMS (6.97) for the test pixels. A scatter-plot showing predicted regeneration age from this ANN against actual years since burning (Fig. 9) indicates that the prediction error is smallest for more recently burned forest. For example, RMS error for forests less than 30 years is 5.85 , while forests more than about 30 years old tend to have their age underpredicted. This bias corresponds to a general increased scattering and flattening of the spectral trajectory plots in Fig. 8, where the reflectance of regeneration gradually becomes less distinct over time (Steyaert et al., 1997).

The best ANN model produced an RMS error that is 1 year less than those from the multiple regression models. This is consistent with the findings of Jensen, Qui, and Ji (1999) and Kimes et al. (1996) where ANN were superior to 


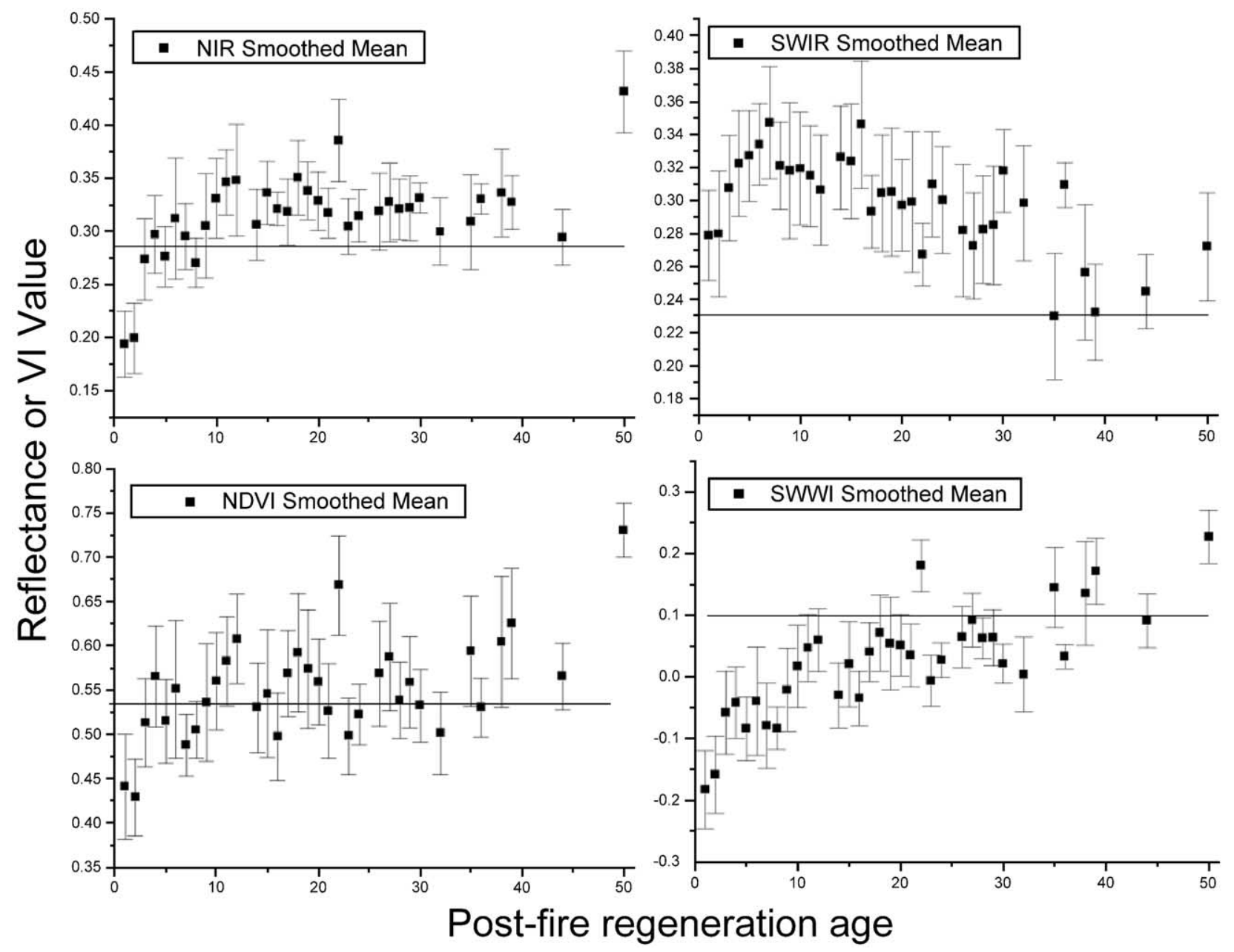

Fig. 8. The relationship between the year of burning (1949-1998) and the mean value for the best multitemporal metric computed from NIR and SWIR channels and two VIs. Error bars represent one standard deviation. The horizontal lines represent the average reflectance or VI for a sample $(n=423)$ of forested pixels in Saskatchewan that were not subject to burning between 1945 and 1999.

regression approaches for predicting conifer forest age using higher resolution Landsat TM data. In these studies, ANN produced RMS errors of 5.6 years for forests up to 45 years old (Kimes et al., 1996) and 1.4 years for forests (aggregated to stand level) up to 40 years old (Jensen et al., 1999). The likely major reason for the consistently better performance of the ANN is that it is highly effective in mapping

Table 2

Results from multiple regression and neural network models

\begin{tabular}{|c|c|c|c|c|}
\hline & \multicolumn{2}{|c|}{ Training pixels } & \multicolumn{2}{|c|}{ Testing pixels } \\
\hline & $\overline{R^{2}}$ & $\begin{array}{l}\text { RMS error } \\
\text { (years) }\end{array}$ & $\overline{R^{2}}$ & $\begin{array}{l}\text { RMS error } \\
\text { (years) }\end{array}$ \\
\hline Multiple regression & .61 & 7.83 & .58 & 8.06 \\
\hline $\begin{array}{l}\text { Multiple regression with } \\
\text { polynomial terms }\end{array}$ & .64 & 7.58 & .57 & 8.21 \\
\hline ANN (10 neurons) & .70 & 6.90 & .69 & 6.97 \\
\hline
\end{tabular}

Forward stepwise and backward elimination regression models produced identical results. Results are shown for the neural network model with the smallest RMS error for testing pixels. nonlinear relationships between reflectance and regeneration age. In addition, ANNs are nonparametric and make no assumptions about normality of data or noncollinearity among variables.

The smallest RMS error obtained for predicting regeneration age was 7 years, which suggests that reflectance measured by VGT is not alone sufficient to predict forest regeneration age with a high level of accuracy. Clearly, several factors will combine to produce large spectral variance among regenerating stands of a given age. The rate of recovery and biomass accumulation after fire depends on burn severity, availability of a seed source, site conditions, and climatic factors (Johnson, 1992). Reflectance integrated over VGT's effective resolution (about $4 \mathrm{~km}^{2}$ considering its modulation transfer function) also would be influenced by the degree of burn fragmentation, nonforest subpixel cover such as wetlands and small lakes, and variation in the trajectory and species composition of regeneration (e.g., jack pine, black spruce, and deciduous pioneer species) (Kasischke \& French, 1997; Steyaert et al., 1997). At present, these varia- 


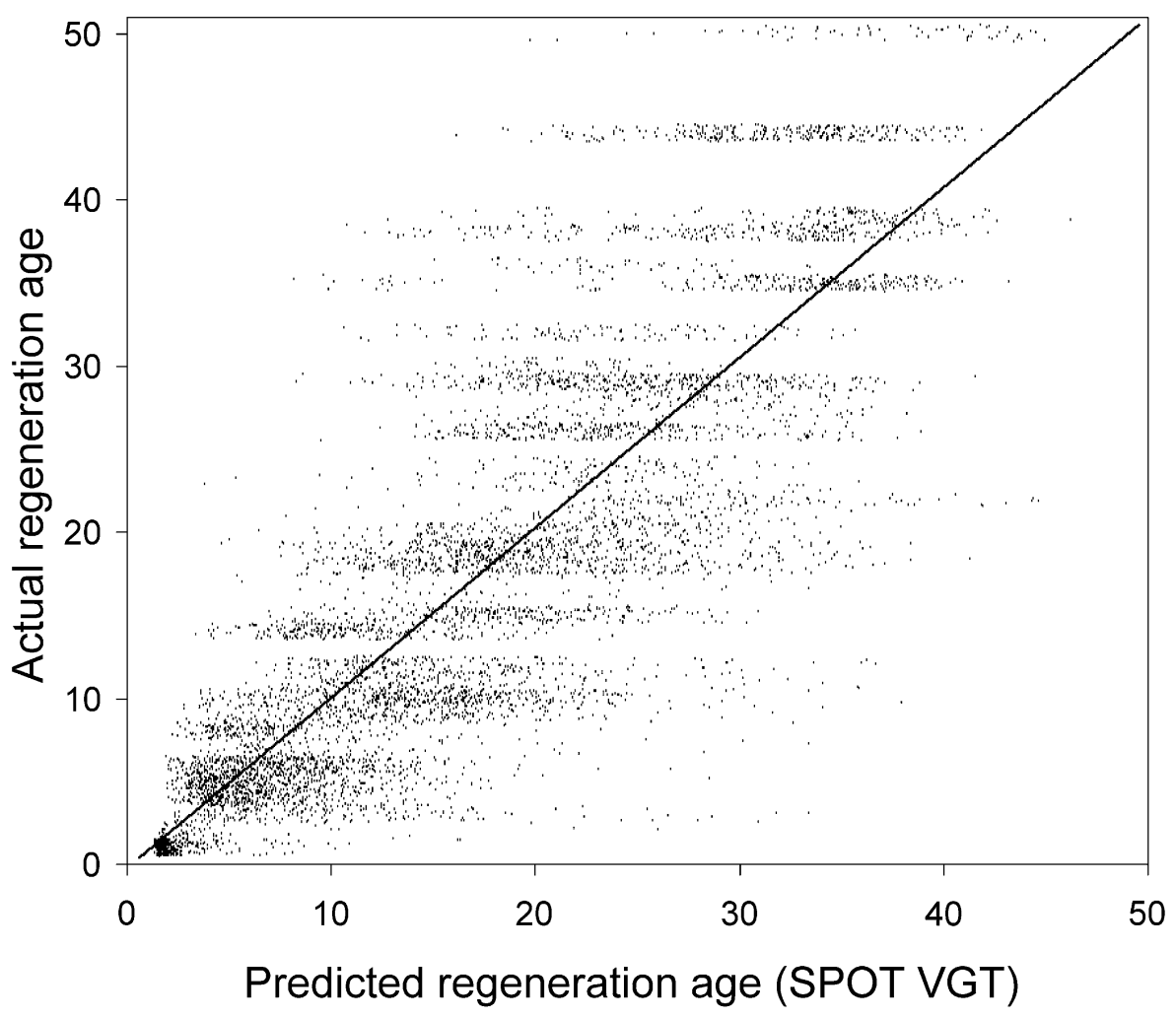

Fig. 9. The relationship between postfire regeneration age predicted using SPOT VGT and an ANN model and actual regeneration age derived from historical forest fire records. A random \pm 0.5 -year jitter has been applied to $y$-axis values to make the distribution of points more apparent. The line on the graph corresponds to 1:1 agreement between predicted and actual year of burning.

bles remain difficult to quantify at regional scales using coarse resolution satellite imagery.

Aboveground biomass of Canadian forests derived using CanFI demonstrated essentially no relation to red, NIR, and SWIR reflectance $\left(R^{2}=.01, .05\right.$, and .09 , respectively, $n=47,435)$ or to the NDVI $\left(R^{2}=.03\right)$. It was, however, weakly associated with the SWVI computed from the NIR and SWIR channels $\left(R^{2}=.25\right)$. Note that $P$ values for all correlations were highly significant $\left(<1^{-85}\right)$, but must be interpreted with caution due to large sample size and high spatial autocorrelation in the $100-\mathrm{km}^{2}$ biomass cells (Moran $I=.92$ and Geary $c=.03$; Sokal \& Oden, 1978). The six ANN models containing between 5 and 35 neurons provided similar accuracy in predicting biomass in the $60 \%$ test set, with the $R^{2}$ between predicted and actual biomass ranging from .79 to .80 and RMS ranging between 32.4 and $32.7 \mathrm{t} /$ ha. Fig. 10 shows a scatter-plot of the results from the network with 35 neurons, which yielded the smallest RMS error (32.4 t/ha) and highest $R^{2}(.80)$. Note that the $R^{2}$ value was inflated due to a cluster of 704 cells ( $4 \%$ of sample shown in Fig. 10 inset) having biomass greater than $250 \mathrm{t} /$ ha, which represented temperate rain forest lying within the Pacific Maritime ecozone. If these cells were not considered in the results, $R^{2}$ decreased to .41 and the RMS error decreased slightly to $29.1 \mathrm{t} / \mathrm{ha}$. The terrestrial ecozone indicator variable was an important stratifying variable in the ANN model, as its removal caused a drop in $R^{2}$ to .64 and an increase in RMS error to $43.5 \mathrm{t} / \mathrm{ha}$. Aggregate bias in biomass prediction for all 18,975 test samples across Canada was negligible, with the ANN predicting a mean biomass of $86.3 \mathrm{t} / \mathrm{ha}$ compared to $86.4 \mathrm{t} / \mathrm{ha}$ from the CanFI-based estimates.

The biomass prediction results based on VGT were poorer than those obtained in a study that used C- and Lband shuttle imaging radar (SIR-C) to predict biomass of boreal forests within the BOREAS study region in Saskatchewan (Ranson et al., 1997). Using SIR-C 30-m resolution channels and stepwise regression, aboveground biomass was estimated with a residual standard error of $16 \mathrm{t} / \mathrm{ha}$. It should be noted, however, that there are currently no spaceborne radar sensors providing the necessary frequencies and polarizations to apply these results operationally over large areas. In another boreal study, Fazakas et al. (1999) estimated tree biomass in Sweden using 658 inventory plots combined with Landsat TM data and an inversesquared distance weighting in feature space. RMS error for an independent validation region was $64.0 \mathrm{t} / \mathrm{ha}$ at the plot level, but progressively decreased to $8.0 \mathrm{t} / \mathrm{ha}$ as all $453 \mathrm{plots}$ were aggregated over the $6-\mathrm{km}^{2}$ validation region. Hall et al. (1997), using a physically based approach and TM data, could estimate black spruce biomass density with an RMS error of $27.3 \mathrm{t} / \mathrm{ha}$ (39.6 t/ha for misclassified sites). 


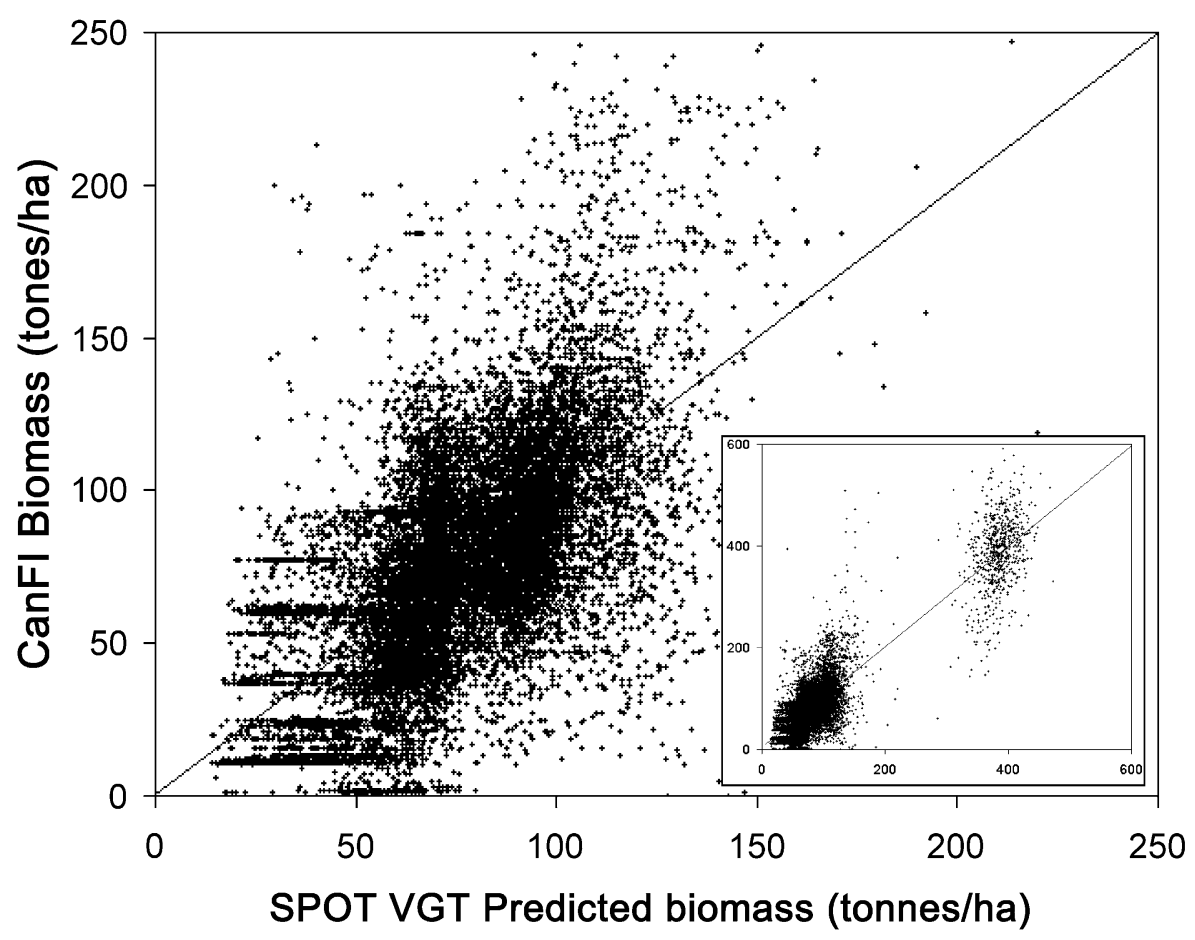

Fig. 10. Relationship between tree biomass predicted using SPOT VGT and an ANN model and biomass based on the CanFI for those 10-km² cells having biomass $<250 \mathrm{t} / \mathrm{ha}$. The inset shows the distribution of all biomass cells, including the $4 \%$ of sample with biomass $>250 \mathrm{t} / \mathrm{ha}$.

In principle, forest reflectance should be more strongly related to biomass by comparison to regeneration age (e.g., Jakubauskas \& Price, 2000; Steininger, 2000), since biomass is more directly linked to stand parameters known to influence reflectance, including leaf area index (LAI), tree density, and tree height (Chen \& Cihlar, 1996; Spanner, Pierce, Peterson, \& Running, 1990; Jakubauskas \& Price, 1997). Yet, in this study, the relative RMS error (RMS error/ mean regeneration age or biomass) for biomass prediction was higher than that for regeneration age (50\% vs. $42 \%)$ if VGT reflectance alone was used as the predictor. One probable reason for this difference is that the age analysis examined only regenerating forests $<50$ years old, in which spectral relationships with LAI and other stand parameters are less likely to be fully saturated (Jakubauskas, 1996; Niemann, 1995; Nilson \& Peterson, 1994). Comparison of the age and biomass results is further confounded by the different spatial scales of the data sets and by certain characteristics of the CanFI data set (Lowe et al., 1996; Gray \& Power, 1997). The 1991 CanFI data were compiled from 47 existing provincial and territorial inventories of variable vintage, having an average age of 11 years at the time the inventory was created or 18 years in relation to the 1998 VGT imagery. Therefore, significant and spatially variable changes will have occurred in biomass density since the source inventories were assembled prior to 1991. In addition, the area inventoried within each biomass cell is not constant and averages $40 \%$. In some remote northerly areas, major gaps in the source coverages were filled using "gap inventories," which are very large polygons with low sampling intensity. Since the location of the inventoried area within each cell is not delineated, we were required to make the assumption that mean reflectance from all $1-\mathrm{km}^{2}$ forested pixels within each $100-\mathrm{km}^{2}$ cell was representative of the normally smaller inventoried area. Despite these limitations in the reference biomass data, our initial results suggest that VGT imagery contains some information-related tree biomass in boreal forests.

\section{Summary and conclusions}

The major findings of this study were as follows.

1. An SWVI combining VGT's NIR and SWIR channels provided superior discrimination of burned from nonburned boreal forest relative to conventional NDVI. However, optimal separability from this index did not occur immediately after burning due a time-lagged increase in SWIR reflectance.

2. Anniversary date differencing of the SWVI index could be combined synergistically with active fire locations from AVHRR to effectively map large boreal burns at continental scales on an annual basis.

3 . The age of regenerating boreal forest after fire could be approximated up to several decades at a regional scale using VGT reflectance and an ANN model. If geographically extendable, this result is significant for studying patterns of fire regeneration and carbon storage in certain remote 
areas of Canada and in Russian boreal forests, where the fire history record is incomplete (Murphy et al., 2000; Shvidenko \& Nilsson, 2000).

4. The SWVI from VGT was weakly correlated with aboveground forest biomass across Canada; however, contemporary forest inventory data will be required to better determine the strength of this relationship. This will be possible with a new plot-based National Forest Inventory for Canada being developed by the Canadian Forest Service (see http://www.pfc.cfs.nrcan.gc.ca/monitoring/inventory/).

\section{Acknowledgements}

SPOT VEGETATION imagery and partial funding were provided through a VEGETATION Preparatory Program investigation led by Jing Chen and Josef Cihlar at CCRS. We thank Martin Siltanen and David Price from the Canadian Forest Service for providing a gridded version of the forest biomass data set and Richard Fernandes at CCRS for reviewing the paper. Robert Landry at CCRS provided the Landsat TM/ETM+ burn boundary vectors.

\section{References}

Amiro, B. D., Todd, J. B., Wotton, B. M., Logan, K. A., Flannigan, M. D. Stocks, B. J., Mason, J. A., Martell, D. L., \& Hirsch, K. G. (2001). Direct carbon emissions from Canadian forest fires, 1959-1999. Canadian Journal of Forest Research, 31, 512-525.

Barbosa, P. M., Gregoire, J. M., \& Pereira, J. M. C. (1999). An algorithm for extracting burned areas from time series of AVHRR GAC data applied at a continental scale. Remote Sensing of Environment, 69, $253-263$.

Barbosa, P. M., Pereira, J. M. C., \& Gregoire, J. M. (1998). Compositing criteria for burned area assessment using multispectral low resolution satellite data. Remote Sensing of Environment, 65, 38-49.

Beaubien, J., Cihlar, J., Simard, G., \& Latifovic, R. (1999). Land cover from multiple thematic mapper scenes using a new enhancement-classification methodology. Journal of Geophysical Research, 104(D22), 27909-27920.

Cahoon, D. R., Stocks, B. J., Levine, J. S., Cofer, W. R., \& Pierson, J. M. (1994). Satellite analysis of the severe 1987 forest fires in northern China and southeastern Siberia. Journal of Geophysical Research, 99, $18627-18638$

Canadian Council of Forest Ministers (1999). National forestry database program. Canadian Forest Service, Natural Resources Canada. 〈http:// nfdp.ccfm.org/ $>$ Ottawa, ON.

Chen, J., \& Cihlar, J. (1996). Retrieving leaf area index of boreal conifer forests using Landsat TM images. Remote Sensing of Environment, 55, $153-162$.

Cihlar, J. (1996). Identification of contaminated pixels in AVHRR composite images for studies of land biosphere. Remote Sensing of Environment, 56, 149-163.

Cihlar, J., Beaubien, J., Latifovic, R., \& Simard, G. (1998). Land cover of Canada Version 1.1. Special Publication, NBIOME Project. Produced by the Canada Centre for Remote Sensing and the Canadian Forest Service, Natural Resources Canada. Available on CD-ROM from the Canada Centre for Remote Sensing, Ottawa, ON.

Cihlar, J., Beaubien, J., Xiao, Q., Chen, J., \& Li, Z. (1997). Land cover of the BOREAS region from AVHRR and Landsat data. Canadian Journal of Remote Sensing, 23, 163-175. de Boer, T. A. (1993). Botanical characteristics of vegetation and their influence on remote sensing. In H. J. Buiten, \& J. G. P. W. Clevers (Eds.), Land observation by remote sensing: theory and applications (pp. 89-103). The Netherlands: Gordon \& Breach Science Publishers.

DeFries, R. S., Hansen, M. C., \& Townshend, J. R. G. (2000). Global continuous fields of vegetation characteristics: a linear mixture model applied to multi-year $8 \mathrm{~km}$ AVHRR data. Remote Sensing of Environment, 60, 228-246.

Eastwood, J. A., Plummer, S. E., Wyatt, B. K., \& Stocks, B. J. (1998). The potential of SPOT-Vegetation data for fire scar detection in boreal forests. International Journal of Remote Sensing, 19, 3681-3687.

Ecological Stratification Working Group (1996). A national ecological framework for Canada. Agriculture and Agri-Food Canada, Research Branch, Centre for Land and Biological Resources Research and Environment Canada, State of Environment Directorate. 〈http://www.ec.gc. ca/soer-ree/English/Framework/framework.cfm $\rangle$ Ottawa, ON.

Eva, H., \& Lambin, E. F. (1998). Burnt area mapping in Central Africa using ATSR data. International Journal of Remote Sensing, 19, 3473-3497.

Fazakas, Z., Nilsson, M., \& Olsson, H. (1999). Regional forest biomass and wood volume estimation using satellite data and ancillary data. Agricultural and Forest Meteorology, 98-99, 417-425.

Flannigan, M. D., \& Vonder Haar, T. H. (1986). Forest fire monitoring using NOAA satellite AVHRR. Canadian Journal of Forest Research, 16, $975-982$

Foody, G. M., Lucas, R. M., Curran, P. J., \& Honzak, M. (1996). Estimation of the areal extent of land cover classes that only occur at a sub-pixel level. Canadian Journal of Remote Sensing, 22, 428-432.

Fraser, R. H., Li, Z., \& Cihlar, J. (2000). Hotspot and NDVI Differencing Synergy (HANDS): a new technique for burned area mapping over boreal forest. Remote Sensing of Environment, 74, 362-376.

Fraser, R. H., Li, Z., \& Landry, R. (2000). SPOT VEGETATION for characterising boreal forest fires. International Journal of Remote Sensing, $21,3525-3532$.

French, N. H., Kasischke, E. S., Stocks, B. J., Mudd, J. P., Martell, D. L., \& Lee, B. S. (2000). Carbon release from fires in the North American boreal forest. In E. S. Kasischke, \& B. J. Stocks (Eds.), Fire, climate change and carbon cycling in the boreal forest. Ecological Studies Series (pp. 377-388). New York: Springer-Verlag.

Gopal, S., Woodcock, C. E., \& Strahler, A. H. (1999). Fuzzy neural network classification of global land cover from a $1^{\circ}$ AVHRR data set. Remote Sensing of Environment, 67, 230-243.

Gray, S., \& Power, K. (1997). Canada's Forest Inventory 1991: the 1994 version-technical supplement. Information Report BC-X-363. Victoria, BC: Canadian Forest Service, Pacific Forestry Centre.

Hall, F. G., Knapp, D. E., \& Huemmrich, K. F. (1997). Physically based classification and satellite mapping of biophysical characteristics in the southern boreal forest. Journal of Geophysical Research, 102(D24), $29567-29580$

Jakubauskas, M. E. (1996). Thematic Mapper characterization of lodgepole pine seral stages in Yellowstone National Park, USA. Remote Sensing of Environment, 56, 118-132.

Jakubauskas, M. E., \& Price, K. P. (1997). Empirical relationships between structural and spectral factors of Yellowstone lodgepole pine forests. Photogrammetric Engineering and Remote Sensing, 63, 1375-1381.

Jakubauskas, M. E., \& Price, K. (2000). Regression-based estimation of lodgepole pine forest age from Landsat Thematic Mapper data. Geocarto International, 15, 19-24.

Jensen, J. R., Qiu, F., \& Ji, M. (1999). Predictive modelling of coniferous forest age using statistical and artificial neural network approaches applied to remote sensor data. International Journal of Remote Sensing, 20, 2805-2822.

Johnson, E. A. (1992). Fire and vegetation dynamics: studies from the North American boreal forest. Cambridge: Cambridge University Press.

Kasischke, E. S. (2000). Boreal ecosystems in the global carbon cycle. In E. S. Kasischke, \& B. J. Stocks (Eds.), Fire, climate change and carbon cycling in the boreal forest. Ecological Studies Series, (pp. 19-30). New York: Springer-Verlag. 
Kasischke, E. S., Christensen, N. L., \& Stocks, B. J. (1995). Fire, global warming, and the carbon balance of boreal forests. Ecological Applications, 5, 437-451.

Kasischke, E. S., \& French, N. H. (1995). Locating and estimating the areal extent of wildfires in Alaskan boreal forests using multiple-season AVHRR NDVI composite data. Remote Sensing of Environment, 51, $263-275$.

Kasischke, E. S., \& French, N. H. (1997). Constraints on using AVHRR composite index imagery to study patterns of vegetation cover in boreal forests. International Journal of Remote Sensing, 18, 2403-2426.

Kaufman, Y. J., \& Remer, L. A. (1994). Detection of forests using mid-IR reflectance: an application for aerosol studies. IEEE Transactions on Geoscience and Remote Sensing, 32, 672-683.

Kimes, D. S., Holben, B. N., Nickeson, J. E., \& McKee, W. A. (1996). Extracting forest age in a Pacific Northwest forest from Thematic Mapper and topographic data. Remote Sensing of Environment, 56, 133-140.

Kimes, D. S., Nelson, R. F., Manry, M. T., \& Fung, A. K. (1998). Attributes of neural networks for extracting continuous vegetation variables from optical and radar measurements. International Journal of Remote Sensing, 19, 2639-2663.

Latifovic, R., Cihlar, J., \& Chen, J. (2002). A comparison of BRDF models for the normalisation of satellite optical data to a standard viewing geometry. IEEE Transactions on Geoscience and Remote Sensing (in press).

Lefsky, M. A., Cohen, W. B., Acker, S. A., Parker, G. G., Spies, T. A., \& Harding, D. (1999). Lidar remote sensing of the canopy structure and biophysical properties of douglas-fir western hemlock forests. Remote Sensing of Environment, 70, 339-361.

Li, Z., Cihlar, J., Moreau, L., Huang, F., \& Lee, B. (1997). Monitoring fire activities in the boreal ecosystem. Journal of Geophysical Research, 102, 29611-29624.

Li, Z., Khananian, A., \& Fraser, R. H. (2001). Detecting smoke from boreal forest fires using neural network and threshold approaches applied to AVHRR imagery. IEEE Transactions on Geoscience and Remote Sensing, 39, 1859-1870.

Li, Z., Nadon, S., \& Cihlar, J. (2000). Satellite-based detection of Canadian boreal forest fires: development and application of the algorithm. International Journal of Remote Sensing, 21, 3057-3069.

Li, Z., Nadon, S., Cihlar, J., \& Stocks, B. J. (2000). Satellite-based mapping of Canadian boreal forest fires: evaluation and comparison of algorithms. International Journal of Remote Sensing, 21, 3071-3082.

Lowe, J. J., Power, K., \& Gray, S. L. (1996). Canada's forest inventory 1991: the 1994 version. An addendum to Canada's Forest Inventory 1991. Information Report BC-X-362E. Victoria, BC: Canadian Forest Service, Pacific Forestry Centre.

Murphy, P. J., Mudd, J. P., Stocks, B. J., Kasischke, E. S., Barry, D., Alexander, M. E., \& French, H. F. (2000). Historical fire records in the North American boreal forest. In E. S. Kasischke, \& B. J. Stocks (Eds.), Fire, climate change and carbon cycling in the boreal forest Ecological Studies Series (pp. 274-288). New York: Springer-Verlag.

Naelapea, O. \& Nickeson, J. (1998). SERM forest fire chronology of Saskatchewan in vector format. Oak Ridge, TN: Oak Ridge National Laboratory, ORNL Distributed Active Archive Center. Available at: http:// www-eosdis.ornl.gov/.

Niemann, K. O. (1995). Remote sensing of forest stand age using airborne spectrometer data. Photogrammetric Engineering and Remote Sensing, $61,1119-1127$.

Nilson, T., \& Peterson, U. (1994). Age dependence of forest reflectance: analysis of main driving factors. Remote Sensing of Environment, 48, 319-331.

Paola, J. D., \& Schowengerdt, R. A. (1995). A review and analysis of backpropagation neural networks for classification of remotely-sensed multi-spectral imagery. International Journal of Remote Sensing, 16, 3033-3058

Penner, M., Power, K., Muhairwe, C., Tellier, R., \& Wang, Y. (1997). Canada's forest biomass resources: deriving estimates from Canada's Forest Inventory. Information Report BC-X-370. Victoria, BC: Canadian Forest Service, Pacific Forestry Centre.

Pereira, J. M. C. (1999). A comparative evaluation of NOAA/AVHRR vegetation indexes for burned surface detection and mapping. IEEE Transactions on Geoscience and Remote Sensing, 37, 217-226.

Pereira, J. M. C., Sa, A. C. L., Sousa, A. M. O., Silva, J. M. N., Santos, T. N., \& Carreiras, J. M. B. (1999). Spectral characterisation and discrimination of burnt areas. In E. Chuvieco (Ed.), Remote sensing of large wildfires (pp. 123-138). Berlin: Springer-Verlag.

Principe, J. C., Euliano, N. R., \& Lefebvre, W. C. (2000). Neural and adaptive systems: fundamentals through simulations. New York: Wiley.

Rahman, H., \& Dedieu, G. (1994). SMAC: a simplified method for the atmospheric correction of satellite measurements in the solar spectrum. International Journal of Remote Sensing, 15, 123-143.

Ranson, K. J., Sun, G., Lang, R. H., Chauhan, N. S., Cacciola, R. J., \& Kilic, O. (1997). Mapping of boreal forest biomass from spaceborne synthetic aperture radar. Journal of Geophysical Research, 102, 29599-29610.

Richter, D.D, O’Neill, K. P., \& Kasischke, E. S. (2000). Postfire stimulation of microbial decomposition in black spruce (Picea mariana L.) forest soils: a hypothesis. In E. S. Kasischke, \& B. J. Stocks (Eds.), Fire, climate change and carbon cycling in the boreal forest. Ecological Studies Series, (pp. 197-213). New York: Springer-Verlag.

Shvidenko, A. Z., \& Nilsson, S. (2000). Extent, distribution, and ecological role of fire in Russian forests. In E. S. Kasischke, \& B. J. Stocks (Eds.), Fire, climate change and carbon cycling in the boreal forest. Ecological Studies Series (pp. 132-150). New York: Springer-Verlag.

Sokal, R. R., \& Oden, N. L. (1978). Spatial autocorrelation in biology: 1. Methodology. Biological Journal of the Linnean Society, 10, 199-228.

Spanner, M. A., Pierce, L. L., Peterson, D. L., \& Running, S. W. (1990). Remote sensing of temperate coniferous forest leaf area index: the influence of canopy closure, understory vegetation and background reflectance. International Journal of Remote Sensing, 11, 95-111.

Steininger, M. K. (2000). Satellite estimation of tropical secondary forest above-ground biomass: data from Brazil and Bolivia. International Journal of Remote Sensing, 21, 1139-1157.

Steyaert, L. T., Hall, F. G., \& Loveland, T. R. (1997). Land cover mapping, fire regeneration, and scaling studies in the Canadian boreal forest with $1 \mathrm{~km}$ AVHRR and Landsat TM data. Journal of Geophysical Research, 102 (D24), 29581-29598.

Stocks, B. J. (1991). The extent and impact of forest fires in northern circumpolar countries. In J. S. Levine (Ed.), Global biomass burning. atmospheric, climatic, and biospheric implications (pp. 197-202). Cambridge, MA: MIT Press.

Stocks, B. J., Zepp, R., \& Knapp, D. (1998). BOREAS TGB-05 fire history of Manitoba 1980 to 1991 in vector format. Oak Ridge, TN: Oak Ridge National Laboratory, ORNL Distributed Active Archive Center. Available at: http://www-eosdis.ornl.gov/.

Watowa, G., \& Trainer, M. (2000). The influence of Canadian forest fires on pollutant concentrations in the United States. Science, 288, 324-328. 